\title{
Fisiopatología de la fibrosis quística
}

\author{
Scott H. Donaldson Richard C. Boucher \\ Centro de Investigación y Tratamiento de la Fibrosis Quística, Universidad de Carolina del Norte en Chapel Hill, \\ Chapel Hill, N.C., EE.UU.
}

\section{Palabras clave}

Fibrosis quística • RTFQ • Canal de sodio epitelial •

Depuración de moco • Transporte de iones - Líquido de la superficie de las vías respiratorias

\section{Extracto}

El conocimiento del desarrollo de la neumopatía en la fibrosis quística (FQ) ha sido la meta perseguida durante varias décadas. Con la clonación del gen regulador de conductancia transmembránica de la FQ (RTFQ) y otros avances en el estudio de la biología de los tejidos epiteliales de las vías respiratorias, se dispone de un cuadro mucho más nítido de la fisiopatología de la enfermedad. Nuestras mejores pruebas señalan la desregulación del transporte de iones como trastorno subyacente, causante de la depleción del volumen de líquido de la superficie de las vías respiratorias, es decir, la deshidratación, y un deterioro asociado de la depuración de moco. A su vez, la mucostasis predispone al pulmón de la FQ a la infección bacteriana, que rápidamente adquiere cronicidad debido a la propia naturaleza de las secreciones de la FQ. La respuesta inflamatoria neutrofílica, no resolutiva, a esta infección crónica causa a su vez una lesión progresiva y permanente de las vías respiratorias, de tal modo que la bronquiectasia y la insuficiencia respiratoria son los procesos corrientes de la neumopatía de la FQ en su fase terminal. El desarrollo de nuevos tratamientos que aborden el trastorno subyacente de la deshidratación de las vías respiratorias constituye la esperanza de prevención de esta cascada de acontecimientos.

\section{KARGER}

Fax +4161306 1234

E-Mail karger@karger.ch

www.karger.com (c) 2006 Nestec Ltd., Vevey/S. Karger AG, Basel

0252-8185/06/0643-0101\$23.50/0

Accesible online en:

www.karger.com/ans

\section{Introducción}

La fibrosis quística (FQ) es la enfermedad genética letal más corriente en las poblaciones blancas. Las mutaciones en el gen regulador de la conductancia transmembránica de la FQ (RTFQ), que se localiza en el brazo largo del cromosoma 7 , confieren a la enfermedad una forma autosómica recesiva. Hasta la fecha, en la Base de Datos de Mutaciones en la Fibrosis Quística (http://www.genet. sickkids.on.ca/cftr/), se han identificado y descrito más de 1.400 mutaciones individuales, haciendo que la detección sistemática de la población meramente a través de técnicas genéticas sea inviable. El alelo mutante $\Delta \mathrm{F} 508$, que codifica la deleción de un solo aminoácido dentro de esta proteína de 1.480 aminoácidos de longitud, es con mucho el alelo más prevalente, dado que representa el $66 \%$ de las mutaciones en todo el mundo [1]. Aunque el fenotipo de la FQ clásica es bastante complejo, implicando múltiples órganos revestidos de epitelio [De Boeck, páginas 124 a 126], las manifestaciones pulmonares son el origen predominante de la morbilidad y la mortalidad. En los últimos años se ha realizado un progreso significativo destinado a comprender mejor la vía que vincula las mutaciones del gen RTFQ con las manifestaciones clínicas de la FQ y, en particular, los mecanismos que subyacen al fallo evidente de la defensa pulmonar. En esta revisión, nos centraremos en los mecanismos fisiopatológicos que permiten que el pulmón de la FQ sea vulnerable al desarrollo de infecciones bacterianas crónicas, y a los acontecimientos subsiguientes que causan la neumopatía bronquiectásica progresiva. 


\section{RTFQ es un regulador del transporte epitelial de sal y agua}

La noción preliminar de que la FQ es el resultado de un transporte anormal de electrolitos procede de observaciones de que el sudor de la FQ contiene concentraciones elevadas de sodio y cloruros [2,3]. Se han obtenido otras pruebas en numerosos estudios, en los que se ha demostrado el transporte anormal de iones a través de otros órganos afectados, entre los que destacan las vías respiratorias [4], los conductos pancreáticos [5], los conductos biliares [6,7] y el colon [8]. La clonación del gen RTFQ [9, 10] y su identificación subsiguiente como canal de cloruros $[11,12]$ representan acontecimientos destacados que consolidaron adicionalmente el vínculo entre la desregulación del transporte de iones y las diversas manifestaciones de la FQ a nivel de órganos. No obstante, el papel del RTFQ en la fisiología epitelial rebasa, tal como se ha demostrado actualmente, su función como canal de $\mathrm{Cl}^{-}$, dado que numerosos estudios han demostrado que el RTFQ participa en la regulación de otros canales iónicos. Merece destacarse que el RTFQ ejerce un efecto inhibidor sobre el canal epitelial de sodio (CENa) [13, 14], a través de un mecanismo que todavía no ha sido determinado, al tiempo que influye también sobre la actividad de otros canales de cloruros bien diferenciados $[15,16]$. En consecuencia, el RTFQ está caracterizado como regulador central del transporte de sal y agua a través de numerosos epitelios, y la consecuencia de su ausencia reside en anomalías del transporte de iones específicas de órganos. Por lo tanto, la reducción de la secreción neta de líquidos a través de los epitelios afectados es un fenómeno común que ocasiona la obstrucción de los conductos (pancreáticos, biliares, bronquiolares y del vas deferens) y la disfunción orgánica subsiguiente (insuficiencia pancreática exocrina, cirrosis, bronquiectasia e infertilidad masculina).

\section{Fisiopatología de la neumopatía de la FQ}

La neumopatía de la FQ se diferencia bien de otras manifestaciones de sistemas de órganos en la FQ por los motivos siguientes: (1) La neumopatía es causa de mortalidad prematura en alrededor del $95 \%$ de los pacientes; (2) sólo el pulmón presenta un fenotipo de infección crónica con una intensa respuesta inflamatoria asociada. En consecuencia, está justificada la discusión adicional de los procesos fisiopatológicos que contribuyen a la neumopatía de la FQ.
Pruebas actuales dan a entender que el pulmón de la FQ no está infectado ni inflamado en el momento del nacimiento [17, 18]. No obstante, en el curso de meses a años comienzan a aparecer estigmas de infección, primero recurrente y luego crónica. Los estudios microbiológicos revelan una evolución de patógenos bastante típica, con predominio en la etapa inicial de la vida de virus respiratorios, Haemophilus influenzae y Staphylococcus aureus. En el trascurso del tiempo, a menudo predominan en el cuadro clínico patógenos más problemáticos y progresivamente resistentes, entre los que destacan Pseudomonas aeruginosa y otras bacterias gramnegativas (por ejemplo, el complejo Burkholderia cepacia, Stenotrophomonas maltophilia y Achromobacter xylosoxidans). La normalidad de las pruebas directas de inmunidad sistémica y la ausencia de fenotipo infectivo fuera de las vías respiratorias permiten suponer que la responsabilidad de la aparición de la neumopatía de la FQ recae en un trastorno local de la defensa pulmonar. De hecho, la intensa respuesta inflamatoria neutrofílica a las infecciones de las vías respiratorias es posiblemente más enérgica y persistente que en condiciones ajenas a la FQ [19, 22], dado que el pulmón de la FQ falla en última instancia en depurar los patógenos bacterianos después de que se hayan establecido. En este trastorno de la defensa congénita de las vías respiratorias se centra la investigación intensiva y el objetivo reciente de hallar tratamientos encaminados a prevenir o retrasar la cascada de acontecimientos patógenos que culminan en la destrucción progresiva del pulmón.

\section{Mecanismos intrínsecos de defensa en el pulmón normal}

Dado que el pulmón está expuesto constantemente a agentes nocivos infectivos, ha evolucionado una defensa multiestratificada capaz de depurar continuamente las vías respiratorias sin inducir una respuesta inflamatoria potencialmente perjudicial. El sistema de depuración del moco (DM) parece tener una importancia capital para la defensa de las vías respiratorias, y es el locus de trastornos que ocasionan enfermedades pulmonares genéticas, como la FQ y la discinesia ciliar primaria. Entre otros elementos importantes de este sistema defensivo destacan leucocitos residentes a nivel local (por ejemplo, macrófagos alveolares y de las vías respiratorias), inmunoglobulinas de las mucosas y compuestos antimicrobianos secretados (por ejemplo, lisozima, lactoferrina), todos los cuales están disponibles para neutralizar los microbios 
que se sustraen a la primera línea de defensa, es decir, la DM mecánica.

El funcionamiento normal del aparato de DM exige las actividades coordinadas de la secreción de moco, el transporte de sal y agua y el impulso ciliar. La secreción de moco crea un manto protector que fija eficientemente las partículas inhaladas a través de su panoplia de epítopos de hidratos de carbono, donde quedan atrapadas a través del flujo turbulento. La capa de moco, que flota en la parte superior de una capa de líquido menos viscosa y bien diferenciada físicamente, es impulsada en dirección superior por una combinación de impulsos ciliares y flujo respiratorio/tos coordinada. La capa de líquido subyacente, a menudo denominada 'sol' o capa de 'líquido periciliar' (LPC), es de por si bastante compleja, y está especialmente estructurada para proporcionar un medio de baja resistencia al impulso ciliar, al tiempo que permite un acoplamiento mecánico eficiente entre los extremos de los cílios y la capa de moco. El transporte iónico activo crea la fuerza impulsora para la absorción y secreción reguladas de líquido [23], que a su vez mantiene una altura apropiada del LPC (que se aproxima a la altura de un cilio desplegado) y la hidratación adecuada de la capa de moco [24]. Tal vez sea más importante el hecho de que el LPC puede funcionar también como un lubrificante que evita la adherencia entre la capa de moco y las superficies de las células, facilitando de este modo la DM, que depende tanto del impulso de los cilios como de la tos [25].

\section{Defecto intrínseco en el hospedante en la FQ}

Se ha planteado un cierto número de hipótesis para explicar la combinación de moco excesivo en las vías respiratorias, infecciones bacterianas típicas (especialmente por $P$. aeruginosa) e inflamación neutrofílica intensa, que es característica de la neumopatía de la FQ. Se ha propuesto el incremento de la fijación bacteriana en las vías respiratorias en la FQ, debido a la alteración de la glucosilación de proteínas luminales [26-28] y la reducción de la fijación mediada por RTFQ, la internalización y la depuración de Pseudomonas [29, 30], para explicar la predisposición de los pacientes afectados de FQ a las infecciones crónicas de las vías respiratorias. No obstante, ninguna de estas hipótesis parece adecuada para explicar el conjunto de la neumopatía de la FQ. En el caso de la hipótesis de la 'alteración de la glucosilación' no se explica la infección que aparece en pacientes con genotipos distintos de $\Delta \mathrm{F} 508 / \Delta \mathrm{F} 508$ [31]. En la última de las hipótesis, donde se propone que el RTFQ actúa como un receptor

Fisiopatología de la FQ de Pseudomonas, no se explica el inicio de la neumopatía clínicamente manifiesta antes de la adquisición de la infección por $P$. aeruginosa. Además, los pacientes con mutaciones del $R T F Q$, que conducen a la expresión de canales en la membrana apical (es decir, mutaciones de 'clase IV'), presentan también un fenotipo infeccioso a pesar de la presencia de un canal de RTFQ de conducción deficiente pero, por lo demás, intacto.

Las explicaciones alternativas de la predisposición inusitada a las infecciones pulmonares en la FQ se han centrado en la hipótesis de que la composición de las propias secreciones de las vías respiratorias en la FQ es normal. En estudios preliminares se ha comunicado que el líquido de la superficie de las vías respiratorias (LSVR) en la FQ es relativamente hipertónico (frente al LSVR normal) y, en consecuencia, representa un medio deficiente para la función de los antimicrobianos sensibles a la sal (defensinas) $[32,33]$. No obstante, estos estudios han sido desechados en gran medida en virtud de estudios minuciosos en los que se demuestra uniformemente la isotonicidad del LSVR (normal y en la FQ) [34-38] y de que las moléculas antimicrobianas dominantes (por ejemplo, lactoferrina y lisozima) permanecen intactas en la FQ [39]. Se planteó una hipótesis 'composicional' adicional para explicar que el deterioro de la defensa del hospedante en la FQ se relaciona con la pérdida de la secreción de bicarbonato a través del RTFQ. Aunque en algunos estudios se indica que el $\mathrm{pH}$ de las secreciones de la superficie de las vías respiratorias puede ser menor en la FQ [4042], el mecanismo o mecanismos precisos por los cuales este fenómeno puede dar lugar a la infección de las vías respiratorias no se conoce en todos sus extremos.

En contraste con estas hipótesis 'biológica celular' y 'composicional del LSVR', la hipótesis actualmente preferida de 'volumen bajo del LSVR' relaciona directamente las anomalías del transporte de iones descritas previamente con el deterioro de la DM. En los epitelios de las vías respiratorias en la FQ se pierden dos funciones del RTFQ. En primer lugar, la ausencia de la influencia inhibidora mediada por RTFQ sobre el CENa. Como consecuencia, la absorción de sodio discurre de un modo irrefrenable, independientemente del estado del volumen del LSVR. En segundo lugar, se pierde la capacidad para iniciar la secreción de $\mathrm{Cl}^{-}$a través del RTFQ en respuesta a la depleción del volumen de LSVR. Por lo tanto, mientras que los epitelios normales de las vías respiratorias combinan absorción de sodio y secreción de cloruros en respuesta a las concentraciones de adenosina en las superficies de las vías respiratorias (a través de receptores $\mathrm{A}_{2 \mathrm{~b}}$, que fijan adenosina y regulan los niveles de AMPc), con

Ann Nestlé [Esp] 2006;64:101-109 
Fig. 1. Las células epiteliales de las vías respiratorias normales regulan el transporte de sodio (a través de CENa) y cloruros (a través de RTFQ y CCAC) con objeto de mantener una altura óptima de la capa de líquido periciliar para apoyar el movimiento ciliar e hidratar adecuadamente la capa de moco subyacente. Como consecuencia, la DMC se mantiene. En los epitelios de la FQ falta el transporte de cloruros mediado por RTFQ y se hiperabsorbe sodio (a través de CENa). A pesar de la compensación parcial por la secreción de cloruros a través de CCAC, se produce la depleción delacapadeLPCyladeshidratación de moco y, como consecuencia, se retrasa la DMC.

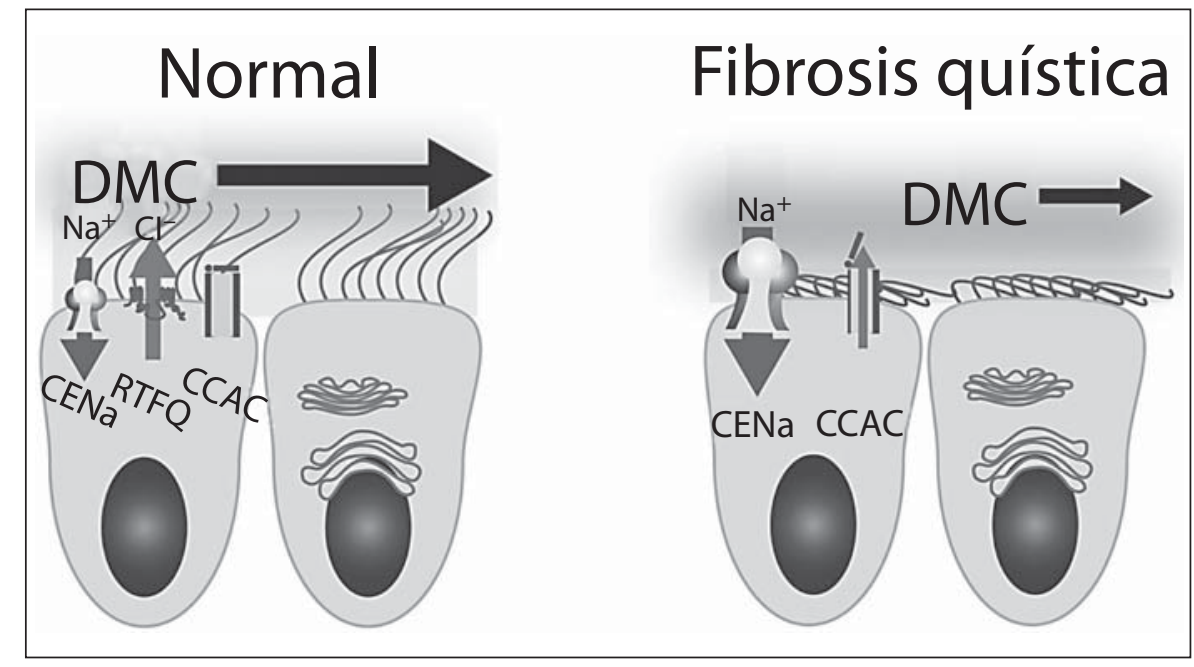

objeto de regular la cantidad de líquido sobre las superficies de las vías respiratorias [43], los epitelios en la FQ no son capaces de proceder de este modo eficazmente [44]. Por lo contrario, dado que los epitelios de las vías respiratorias son permeables al agua, la combinación de una hiperabsorción de sodio y una secreción de cloruros insuficiente produce una reducción del volumen del LSVR isotónico. Con la depleción del volumen, el LPC llega a ser demasiado superficial para permitir el movimiento ciliar normal, y la depuración a través de este mecanismo se pierde (fig. 1). Además, la depleción del LPC puede permitir el contacto entre la capa de moco suprayacente y las superficies celulares, propiciando el desarrollo de interacciones adhesivas entre las mucinas de la superficie celular (trabadas) y los componentes del moco secretado. Como consecuencia, se deteriora la DM, tanto dependiente de los cilios como dependiente de la tos. Por último, la deshidratación de la capa de moco incrementa su viscoelasticidad, reduciendo de este modo su transportabilidad. La concentración de mucinas dentro de la capa de moco también estrecha la malla a través de la cual los neutrófilos reclutados deben emigrar para acceder a las bacterias intraluminales, dando lugar a un trastorno adicional de la defensa del hospedante [45]. En consecuencia, esta serie de acontecimientos constituye la base fisiopatológica del inicio de la enfermedad en la FQ y resulta en estasis de moco y formación de placas de moco adherentes sobre las superficies de las vías respiratorias. Estas placas proporcionan el medio en el cual bacterias específicas son capaces de persistir y causar neumopatía supurativa crónica (fig. 2).
Dada la importancia de la DM para la defensa pulmonar, no debe sorprender la presencia de una vía secretora de líquidos redundante en las vías respiratorias, concretamente canales de cloruros activados por calcio (CCAC), que son estimulados por la unión de la adenosina $5^{\prime}$-trifosfato (ATP) a receptores $\mathrm{P}_{2} \mathrm{Y}_{2}$. El ATP es liberado a partir de células epiteliales, más notablemente en respuesta a estímulos físicos, como el esfuerzo cortante débil impartido por el flujo respiratorio durante la respiración corriente y la tos [44]. En estudios recientes se da a entender que este sistema es funcional en las vías respiratorias en la FQ y puede proporcionar una hidratación de la superficie de las vías respiratorias suficiente, aunque inferior a la normal, para la DM [44]. No obstante, la mera dependencia de este mecanismo para mantener el volumen del LSVR en la FQ llega a ser particularmente problemática cuando agresiones (por ejemplo, infección vírica) perturban la vía de transmisiones de señales de ATP cuidadosamente regulada. El aumento de la expresión de enzimas que hidrolizan el ATP aparece en respuesta a diversos estímulos inflamatorios [46] y, en el caso de la infección experimental por el virus sincitial respiratorio, se ha observado que reduce los niveles de ATP y causa la depleción del volumen del LSVR [44] (fig. 3). En consecuencia, se ha indicado que agresiones episódicas a las vías respiratorias en la FQ causan la descomposición del sistema de regulación del volumen del LSVR y resultan en un deterioro regional de la DM. Además, se ha informado de que 'exacerbaciones' de la neumopatía de la FQ pueden ser la expresión clínica de estos acontecimientos episódicos. En el trascurso del tiempo, estas agresiones pueden crear un ciclo de automantenimiento de la reducción de la depu- 


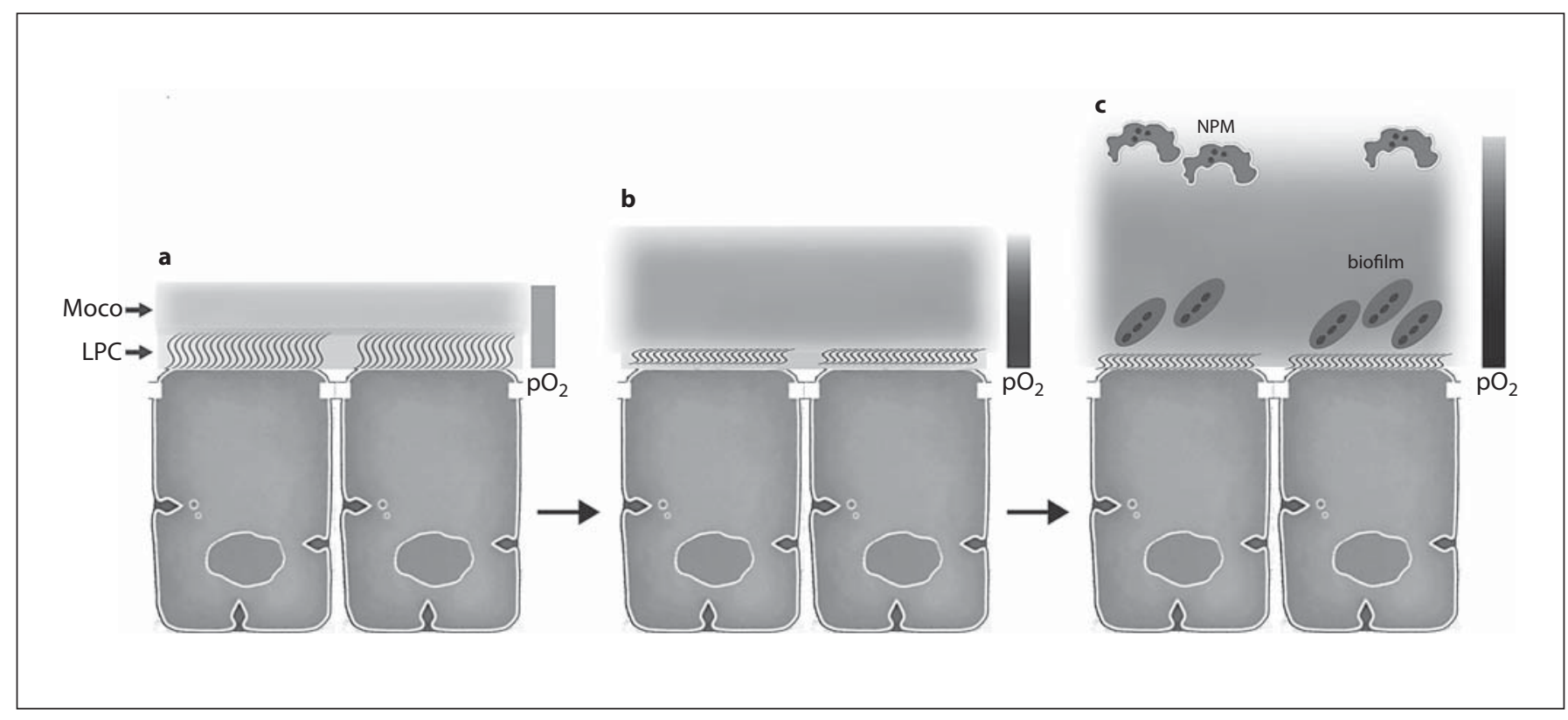

Fig. 2. a El pulmón normal mantiene una capa de LPC cuya altura se aproxima a la de un cilio desplegado, hidrata normalmente la capa de moco, y las secreciones de las superficies de las vías respiratorias son aerobias. b Al principio de la neumopatía de la FQ, las anomalías del transporte de iones causan la depleción de la capa de LPC evitando el movimiento normal de los cilios y causando el espesamiento de la capa de moco para comenzar a interferir con los cilios. c En la neumopatía de la FQ avanzada se acu- mula una masa de moco notablemente deshidratada y anaerobia en la luz de las vías respiratorias, que llega a adherirse a la superficie de las vías respiratorias debido a la pérdida de la capa de LPC, y propicia el crecimiento de microcolonias de Pseudomonas en una estructura de biofilm. Los neutrófilos reclutados son incapaces de penetrar en la capa de moco espesada y, en consecuencia, no acceden a las bacterias dentro del tapón de moco. ración e infección bacteriana crónica, lo cual explicaría la progresión crónica observada de la neumopatía de la FQ.

Las pruebas de validez de la hipótesis del 'bajo volumen' provienen de numerosos sistemas de modelos in vitro, así como de mediciones in vivo, que han validado las predicciones de que el LSVR es isotónico [34, 37, 47], que el LPC es vaciado en la FQ en relación con los epitelios normales $[24,34]$ y que la estasis y la adherencia de moco aparecen como consecuencia de la depleción del volumen de LPC [34]. Además, la mucosa del tabique nasal del ratón knockout RTFQ, que es la única región de las vías respiratorias que demuestra el fenotipo típico del transporte iónico en la FQ, desarrolla un fenotipo local similar a FQ con reducción de la altura del LSVR y signos de infección/inflamación espontánea [24]. Más recientemente, se ha creado un ratón transgénico que sobrexpresa la subunidad $\beta$ de CENa para modelar mejor la hiperabsorción de volumen que se observa en las vías respiratorias de la FQ humana. Como resultado se obtenía un animal con un llamativo fenotipo similar a FQ, en el que desta- caba lo siguiente: (1) hiperabsorción de sodio, demostrable a través de las vías respiratorias; (2) depleción del volumen del LSVR; (3) hipersecreción y adherencia de moco en las vías respiratorias; (4) inflamación 'espontánea' (es decir, que no requería una inoculación experimental con un agente infeccioso) y (5) retraso de la depuración bacteriana [48].

Las mediciones in vivo de la depuración mucociliar (DMC) en pacientes afectados de FQ proporcionan interesantes conocimientos adicionales de la fisiopatología de la neumopatía de la FQ, así como una prueba de la hipótesis de reducción de la DM. El mayor conjunto de datos que describe la DMC en la FQ es el de Robinson y cols. [49], que deja entrever que la DMC es sistemáticamente anormal en los pacientes afectados de FQ, incluyendo a los que presentan valores espirométricos normales. Esta observación permite suponer que la DM es, de hecho, un trastorno de la FQ precoz, probablemente primario, en lugar de una consecuencia secundaria de la neumopatía. En contraste, los datos de Donaldson y cols. [50], comunicados más recientemente, dan a entender 


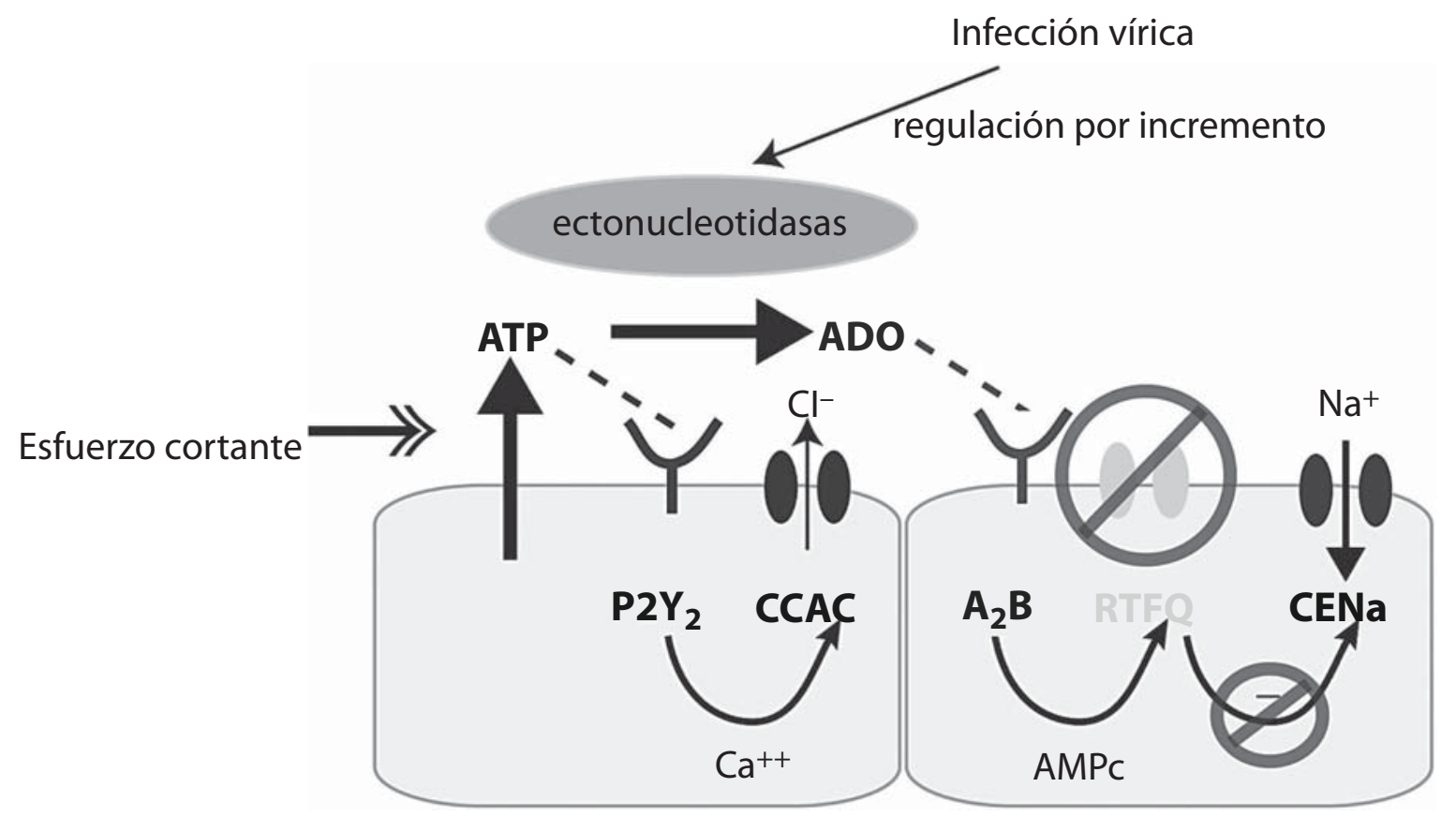

Fig. 3. Los epitelios de la FQ dependen de la secreción de cloruros mediada por ATP para la formación del LSVR. El esfuerzo cortante, inducido por el flujo respiratorio sobre las superficies de las vías respiratorias, da lugar a la liberación de ATP, que se une a receptores $\mathrm{P}_{2} \mathrm{Y}_{2}$ y estimula la secreción de cloruros a través de CCAC. Las ectonucleotidasas degradan el ATP liberado, limitando su efecto. En el contexto de la infección vírica u otros estímulos inflamatorios, las ectonucleotidasas son reguladas por incremento, el metabolismo del ATP aumenta y la capacidad para segregar cloruros y agua (a través de CCAC) resulta deteriorada en las vías respiratorias de la FQ. Cabe destacar que la formación de adenosina no estimula la secreción de cloruros y agua en las vías respiratorias de la FQ debido a la ausencia de RTFQ. $\mathrm{A}_{2} \mathrm{~B}=$ receptor de adenosina $\mathrm{A}_{2} \mathrm{~B} ; \mathrm{ADO}=$ adenosina. que la DMC en las grandes vías respiratorias de sujetos afectados de FQ no difería de la normalidad, mientras que los trastornos de la depuración se detectaban en medidas que reflejan la depuración de las vías respiratorias pequeñas (es decir, depuración pulmonar periférica y mediciones de la depuración durante 24 horas). Además, en este estudio se demostró que la depuración mediada por la tos era desdeñable en las vías respiratorias periféricas en la FQ. En consecuencia, estos datos confirieron un respaldo adicional al concepto de que la DM es anormal en la FQ, pero que el trastorno puede ser heterogéneo y más acusado en las regiones de las vías respiratorias pequeñas, que se suponen el origen de la neumopatía de la FQ.

\section{La progresión de la neumopatía de la FQ: más allá de la deshidratación del LSVR}

Con la deshidratación de las superficies de las vías respiratorias de la FQ y la formación de placas de moco, se crean las condiciones favorables para la aparición de infección bacteriana crónica y la subsiguiente respuesta inflamatoria. Las propias placas, al ser estáticas y relativamente impenetrables a los neutrófilos, crean un nicho ideal para las bacterias inhaladas o aspiradas desde la orofaringe. A medida que se acumula moco en estas placas se forma un tapón ostensible y aparece una obstrucción de las vías respiratorias, propiciando adicionalmente el establecimiento de la infección bacteriana. Es importante destacar la creación de un nicho anaerobio local de placas y tapones de moco macroscópicos como conse- 
cuencia tanto de una larga distancia de difusión de $\mathrm{O}_{2}$ como de tasas elevadas de consumo de $\mathrm{O}_{2}$ por el epitelio de la $\mathrm{FQ}$, tal como demuestran estudios in vitro e in vivo (broncoscópicos) [51]. Se cree que este microambiente selecciona los patógenos que mejor se adaptan al mismo, incluyendo Pseudomonas, lo que explica la constatación de que la $F Q$, y en cierta menor medida otras formas de bronquiectasia, es afectada por un conjunto relativamente escaso pero único de patógenos típicos. Merece destacarse la probabilidad de que la complejidad de las poblaciones bacterianas que aparecen en este entorno resulte espectacularmente subestimada con el empleo de técnicas microbiológicas de rutina. Más recientemente, técnicas moleculares han demostrado una diversidad bacteriana muy superior en el pulmón en FQ con respecto a criterios previos, comprendiendo la presencia de microorganismos que exigen condiciones anaerobias para su crecimiento [52].

La nueva información referente al comportamiento de Pseudomonas en el pulmón de la FQ ha sido muy útil en cuanto al conocimiento de la fisiopatología de la FQ, al tiempo que ha aportado esperanzas de nuevos objetivos terapéuticos. En su ámbito natural, Pseudomonas es una bacteria planctónica móvil. Las pseudomonas alteran drásticamente su expresión génica, por lo menos en parte debido a señales de percepción de quórum, de manera que aparece una microcolonia bacteriana estacionaria o biofilm, dentro de las placas/tapones de moco. Tanto la producción de alginato, la conversión a metabolismo anaerobio y el propio entorno de mucina concentrada contribuyen a la evasión de defensas inmunitarias e intervenciones antibióticas y resultan en una persistencia bacteriana en el pulmón de la FQ. La ineficaz respuesta inflamatoria consiguiente, en lugar de despejar la infección causa lesiones progresivas en las vías respiratorias y bronquiectasia.

\section{Consecuencias terapéuticas}

Los estudios que abordan la patogénesis de la neumopatía de la FQ no sólo han fomentado nuestro conocimiento de este proceso complejo sino que han descubierto también nuevos objetivos terapéuticos para el desarrollo de fármacos. Evidentemente, las normas terapéuticas de depuración física de las vías respiratorias y la administración de antibióticos son medidas lógicas para reducir al mínimo la masa de moco retenido y la obstrucción de las vías respiratorias, al tiempo que reducen también la carga de microorganismos infectivos, que estimula más inflamación y producción de moco. No obstante, en la actualidad, es evidente que intervenciones que restablecen el estado de hidratación normal de las capas de LPC y moco antes de la aparición de la adherencia del moco conllevan el potencial de retrasar considerablemente el inicio y la progresión de la neumopatía de la FQ. Con este fin, actualmente se utilizan en clínica soluciones salinas hipertónicas inhaladas que arrastran osmóticamente agua hacia la capa del LSVR. Este abordaje representa la primera generación de tratamientos encaminados realmente al trastorno subyacente de la FQ. De un modo satisfactorio, este simple enfoque terapéutico ha demostrado que mejora la DMC y la espirometria, mientras que reduce también los síntomas y, lo que es más importante, la frecuencia de las exacerbaciones patológicas [50, 53; Strandvik, p. 136].

En fase de desarrollo se hallan actualmente otros agentes que abordan la depleción del volumen de LSVR a través de otros mecanismos de acción. Por ejemplo, se están realizando ensayos clínicos con los agonistas de $\mathrm{P}_{2} \mathrm{Y}_{2}$ de acción prolongada (que estimulan la secreción de cloruros a través de CCAC) y con inhibidores de la CENa, fármacos que conllevan el potencial de reequilibrar la secreción/absorción del líquido a través de las vías respiratorias de la FQ utilizando el aparato de transporte iónico inmediatamente disponible. Alternativamente, los esfuerzos intensivos basados en el uso de la detección sistemática de alto rendimiento de bibliotecas químicas están comenzando a identificar agentes que mejoran la trasformación y la función celulares del canal RTFQ del mutante más corriente (es decir, $\Delta \mathrm{F} 508$ ), de manera que pueda acceder a la membrana plasmática apical y funcionar como un canal de cloruros [54]. Es probable que sea necesario el uso precoz y coherente (es decir, en la lactancia o antes del inicio de una neumopatía significativa) de cualquier tratamiento que aborde eficazmente la depleción del volumen del LSVR. No obstante, esta estrategia proporciona actualmente, por vez primera, la oportunidad de intervenir de un modo preventivo, en lugar de reactivo, y alterar de este modo significativamente el curso de esta neumopatía mortal. Cabe esperar a corto plazo la realización de ensayos clínicos que verifiquen este enfoque terapéutico en los pacientes más jóvenes.

\section{Conclusión}

Aunque se ha propuesto cierto número de hipótesis referidas al origen de la neumopatía de la FQ, cada vez es mayor el número de pruebas disponibles de que la deple- 
ción del volumen del LSVR, junto a la adherencia del moco espesado a las superficies de las vías respiratorias, inicia la compleja cascada de acontecimientos que culmina en infección crónica, bronquiectasia e insuficiencia respiratoria. Estos datos proporcionan un impulso para abordar precozmente las etapas patogenéticas con agentes que incrementen el volumen del LSVR y despeguen las placas de moco adherentes. Además, las estrategias basadas en Pseudomonas adaptada a un medio anaerobio y el crecimiento de biofilm pueden proporcionar tratamien- tos perfeccionados para pacientes que presenten ya una neumopatía manifiesta con infección bacteriana persistente. No obstante, en última instancia, la administración de tratamientos de acción prolongada que restablezcan eficazmente la hidratación de las superficies de las vías respiratorias antes de que aparezca la enfermedad cróni$\mathrm{ca}$, puede ser necesaria para reducir considerablemente la carga que impone esta enfermedad a los pacientes afectados de FQ.

\section{Bibliografía}

1 Tsui LC: Cystic fibrosis mutation database. http://www.genet.sickkids.on.ca/cftr/.

-2 di Sant' Agnese PA, Darling RC, Perera GA: Abnormal electrolyte composition of sweat in cystic fibrosis of the pancreas. Pediatrics 1953;12:549-563.

3 Quinton PM: chloride impermeability in cystic fibrosis. Nature 1983;301:421-422.

4 Knowles MR, Stutts MJ, Spock A, et al: Abnormal ion permeation through cystic fibrosis respiratory epithelium. Science 1983;221: 1067-1070.

5 Kopelman H, Durie P, Gaskin K, et al: Pancreatic fluid secretion and protein hyperconcentration in cystic fibrosis. N Engl J Med 1985;312:329-334.

6 Fitz JG, Basavappa S, McGill J, et al: Regulation of membrane chloride currents in rat bile duct epithelial cells. J Clin Invest 1993; 91:319-328.

7 Cohn JA, Strong TV, Picciotto MR, et al: Localization of the cystic fibrosis transmembrane conductance regulator in human bile duct epithelial cells. Gastroenterology 1993; 105:1857-1864.

8 Gowen CW Jr, Gowen MA, Knowles MR: Colonic transepithelial potential difference in infants with cystic fibrosis. J Pediatr 1991; 118:412-415.

-9 Riordan JR, Rommens JM, Kerem B, et al: identification of the cystic fibrosis gene: cloning and characterization of complementary DNA. Science 1989;245:1066-1073.

-10 Rommens JM, Iannuzzi MC, Kerem B, et al: Identification of the cystic fibrosis gene: chromosome walking and jumping. Science 1989;245:1059-1065.

- 11 Bear CE, Li CH, Kartner N, et al: Purification and functional reconstitution of the cystic fibrosis transmembrane conductance regulator (CFTR). Cell 1992;68:809-818.

-12 Kartner N, Hanrahan JW, Jensen TJ, et al: expression of the cystic fibrosis gene in nonepithelial invertebrate cells produces a regulated anion conductance. Cell 1991;64:681691.
13 Stutts MJ, Rossier BC, Boucher RC: Cystic fibrosis transmembrane conductance regulator inverts protein kinase A-mediated regulation of epithelial sodium channel single channel kinetics. J Biol Chem 1997;272: 14037-14040.

14 Stutts MJ, Canessa CM, Olsen JC, et al: CFTR as a CAMP-dependent regulator of sodium channels. Science 1995;269:847-850.

15 Tarran R, Loewen ME, Paradiso AM, et al: Regulation of murine airway surface liquid volume by CFTR and $\mathrm{Ca}^{2+}$-activated $\mathrm{Cl}^{-}$ conductances. J Gen Physiol 2002;120:407418.

16 Schwiebert EM, Egan ME, Hwang TH, et al: CFTR regulates outwardly rectifying chloride channels through an autocrine mechanism involving ATP. Cell 1995;81:10631073.

17 Armstrong DS, Grimwood K, Carlin JB, et al: Lower airway inflammation in infants and young children with cystic fibrosis. Am J Respir Crit Care Med 1997;156:1197-1204.

18 Dakin CJ, Numa AH, Wang H, et al: Inflammation, infection, and pulmonary function in infants and young children with cystic fibrosis. Am J Respir Crit Care Med 2002;165: 904-910.

19 Noah TL, Black HR, Cheng PW, et al: Nasal and bronchoalveolar lavage fluid cytokines in early cystic fibrosis. J Infect Dis 1997;175: 638-647.

20 Muhlebach MS, Stewart PW, Leigh MW, Noah TL: Quantitation of inflammatory responses to bacteria in young cystic fibrosis and control patients. Am J Respir Crit Care Med 1999;160:186-191.

21 Khan TZ, Wagener JS, Bost T, et al: Early pulmonary inflammation in infants with cystic fibrosis. Am J Respir Crit Care Med 1995; 151:1075-1082.

22 Bonfield TL, Konstan MW, Berger M: Altered respiratory epithelial cell cytokine production in cystic fibrosis. J Allergy Clin Immunol 1999;104:72-78.
23 Tarran R, Grubb BR, Gatzy JT, et al: The relative roles of passive surface forces and active ion transport in the modulation of airway surface liquid volume and composition. J Gen Physiol 2001;118:223-236.

24 Tarran R, Grubb BR, Parsons D, et al: The CF salt controversy: in vivo observations and therapeutic approaches. Mol Cell 2001;8: 149-158.

25 Raviv U, Giasson S, Kampf N, et al: Lubrication by charged polymers. Nature $2003 ; 425$ : 163-165.

26 Rhim AD, Stoykova L, Glick MC, Scanlin TF: Terminal glycosylation in cystic fibrosis (CF): a review emphasizing the airway epithelial cell. Glycoconj J 2001;18:649-659.

27 Scanlin TF, Glick MC: Terminal glycosylation in cystic fibrosis. Biochim Biophys Acta 1999;1455:241-253.

28 Bryan R, Kube D, Perez A, et al: Overproduction of the CFTR R domain leads to increased levels of asialoGM1 and increased Pseudomonas aeruginosa binding by epithelial cells. Am Respir Cell Mol Biol 1998;19:269-277.

29 Pier GB, Grout M, Zaidi TS, et al: Role of mutant CFTR in hypersusceptibility of cystic fibrosis patients to lung infections. Science 1996;271:64-67.

30 Schroeder TH, Reiniger N, Meluleni G, et al: Transgenic cystic fibrosis mice exhibit reduced early clearance of pseudomonas aeruginosa from the respiratory tract. J Immunol 2001;166:7410-7418.

31 Zar H, Saiman L, Quittell L, Prince A: Binding of Pseudomonas aeruginosa to respiratory epithelial cells from patients with various mutations in the cystic fibrosis transmembrane regulator. J Pediatr 1995; 126:230-233.

-32 Smith JJ, Travis SM, Greenberg EP, Welsh MJ: Cystic fibrosis airway epithelia fail to kill bacteria because of abnormal airway surface fluid. Cell 1996;85:229-236

33 Goldman MJ, Anderson GM, Stolzenberg $\mathrm{ED}$, et al: Human beta-defensin-1 is a saltsensitive antibiotic in lung that is inactivated in cystic fibrosis. Cell 1997;88:553-560. 
\$3 Matsui H, Grubb BR, Tarran R, et al: Evidence for periciliary liquid layer depletion, not abnormal ion composition, in the pathogenesis of cystic fibrosis airways disease. Cell 1998;95:1005-1015.

35 Grubb BR, Chadburn JL, Boucher RC: In vivo microdialysis for determination of nasal liquid ion composition. Am J Physiol Cell Physiol 2002;282:C1423-C1431.

36 Knowles MR, Robinson JM, Wood RE, et al: Ion composition of airway surface liquid of patients with cystic fibrosis as compared with normal and disease-control subjects. J Clin Invest 1997;100:2588-2595.

37 Jayaraman S, Song YL, Vetrivel L, et al: Noninvasive in vivo fluorescence measurement of airway-surface liquid depth, salt concentration, and pH. J Clin Invest 2001;107:317324.

38 Caldwell RA, Grubb BR, Tarran R, et al: In vivo airway surface liquid $\mathrm{Cl}$ - analysis with solid-state electrodes. J Gen Physiol 2002; 119:3-14.

-39 Travis SM, Conway BA, Zabner J, et al: Activity of abundant antimicrobials of the human airway. Am J Respir Cell Mol Biol 1999; 20:872-879.

40 Tate S, MacGregor G, Davis M, et al: Airways in cystic fibrosis are acidified: detection by exhaled breath condensate. Thorax 2002;57: 926-929.
41 Song Y, Salinas D, Nielson DW, Verkman AS: Hyperacidity of secreted fluid from submucosal glands in early cystic fibrosis. Am J Physiol Cell Physiol 2006;290:C741-C749.

42 Coakley RD, Grubb BR, Paradiso AM, et al: Abnormal surface liquid $\mathrm{pH}$ regulation by cultured cystic fibrosis bronchial epithelium. Proc Natl Acad Sci USA 2003;100: 16083-16088.

43 Lazarowski ER, Tarran R, Grubb BR, Van Heusden CA, et al: Nucleotide release provides a mechanism for airway surface liquid homeostasis. J Biol Chem 2004;279:3685536864.

44 Tarran R, Button B, Picher M, et al: Normal and cystic fibrosis airway surface liquid homeostasis: the effects of phasic shear stress and viral infections. J Biol Chem 2005;280 35751-35759.

45 Matsui H, Verghese MW, Kesimer M, et al: Reduced three-dimensional motility in dehydrated airway mucus prevents neutrophil capture and killing bacteria on airway epithelial surfaces. J Immunol 2005;175:10901099.

46 Picher M, Burch LH, Boucher RC: Metabolism of $\mathrm{P} 2$ receptor agonists in human airways: implications for mucociliary clearance and cystic fibrosis. J Biol Chem 2004;279: 20234-20241.

47 Jayaraman S, Song YL, Verkman AS: Airway surface liquid osmolality measured using fluorophore-encapsulated liposomes. J Gen Physiol 2001;117:423-430.
48 Mall M, Grubb BR, Harkema JR, et al: Increased airway epithelial $\mathrm{Na}^{+}$absorption produces cystic fibrosis-like lung disease in mice. Nat Med 2004;10:487-493.

49 Robinson M, Eberl S, Tomlinson C, et al: Regional mucociliary clearance in patients with cystic fibrosis. J Aerosol Med 2000;13: 73-86.

50 Donaldson SH, Bennett WD, Zeman KL, et al: Mucus clearance and lung function in cystic fibrosis with hypertonic saline. $\mathrm{N}$ Engl J Med 2006;354:241-250.

51 Worlitzsch D, Tarran R, Ulrich M, et al: Effects of reduced mucus oxygen concentration in airway pseudomonas infections of cystic fibrosis patients. J Clin Invest 2002; 109:317-325.

52 Rogers GB, Carroll MP, Serisier DJ, et al: Characterization of bacterial community diversity in cystic fibrosis lung infections by use of $16 \mathrm{~s}$ ribosomal DNA terminal restriction fragment length polymorphism profiling. J Clin Microbiol 2004;42:5176-5183.

53 Elkins MR, Robinson M, Rose BR, et al: A controlled trial of long-term inhaled hypertonic saline in patients with cystic fibrosis. $\mathrm{N}$ Engl J Med 2006;354:229-240.

54 Pedemonte N, Lukacs GL, Du K, et al: Smallmolecule correctors of defective deltaF508CFTR cellular processing identified by highthroughput screening. J Clin Invest 2005; 115:2564-2571. 